\title{
STRATEGI PENGHIMPUNAN DANA ZAKAT LIMA LEMBAGA PENGELOLA ZAKAT DI INDONESIA
}

\section{STRATEGIES FUNDRAISING ZAKAT, FIVE ZAKAT INSTITUTIONS IN INDONESIA}

\author{
A. Aziz ${ }^{1 a}$ dan A. Sukma ${ }^{2}$ \\ 1Program Studi Ekonomi Islam Fakultas Ekonomi Islam Universitas Djuanda, Jl. Tol Ciawi No. 1, \\ Kotak Pos 35 Bogor 16720. \\ 2Program Studi Ekonomi Islam Fakultas Ekonomi Islam Universitas Djuanda, Jl. Tol Ciawi No. 1, \\ Kotak Pos 35 Bogor 16720.
}

\begin{abstract}
This study aims to determine the zakat fund raising strategy in five zakat management institutions in Indonesia. Data analysis method used is the analysis method Spider webs. Based on the analysis of zakat fund raising strategy is the most optimal performed by Dompet Dhuafa. Charity fund raising strategy by opening branches abroad and use the system ATL (Above The Line) and BTL (Below The Line)
\end{abstract}

Keywords: Fundraising, Strategies, Zakat.

\section{ABSTRAK}

Penelitian ini bertujuan untuk mengetahui strategi penghimpunan dana zakat di lima lembaga pengelola zakat di Indonesia. Metode analisis data yang digunakan adalah metode analisis jaring laba-laba (Spyder web analisyst). Berdasarkan hasil analisis strategi penghimpunan dana zakat yang paling optimal dilakukan oleh Dompet Dhuafa yaitu dengan membuka kantor cabang di luar negeri dan menggunakan sistem ATL (Above The Line) dan BTL (Below The Line).

Kata kunci: Strategi, Penghimpunan, Dana Zakat.

Aziz A. 2015. Strategi Penghimpunan Dana Zakat Lima Lembaga Pengelola Zakat di Indonesia. Jurnal Syarikah 2(1): 131-148.

\section{PENDAHULUAN}

Penghimpunan dana zakat merupakan salah satu aktivitas utama dari pengelolaan zakat. Setiap aktivitas dalam pengelolaan zakat diarahkan untuk mencapai tujuan zakat yaitu meningkatkan perekonomian umat dengan cara pengelolaan dana zakat yang berorientasi pada perbaikan kondisi perekonomian mustahik. Namun pengelolaan yang baik pun tidak akan berhasil tanpa dukungan jumlah dana zakat yang memadai. Sehingga menjadi sebuah keharusan bagi lembaga zakat untuk meningkatkan jumlah pengumpulan dana zakatnya agar keterjangkauan dan kemanfaatannya dirasakan lebih meluas.

Penelitian yang dilakukan oleh IPB dan BAZNAS menunjukan bahwa potensi zakat di Indonesia Rp. 217 triliun. Jumlah yang sangat besar tersebut masih belum berbanding lurus dengan realitas atau kenyataan dari pengumpulan dana zakat yang masih berkisar pada angka dibawah 3 
triliun rupiah dalam setiap tahunnya. Saat ini, terdapat 20 Organisasi Pengelola Zakat (OPZ) yang telah disahkan oleh kementrian Agama Republik Indonesia. Jumlah tersebut masih dibawah 10 persen dari total Organisasi Pengelola Zakat yang ada yaitu sekitar 300 OPZ. Semakin banyak jumlah OPZ dengan sebaran yang meluas maka hal ini dapat memberikan keuntungan tersendiri dalam hal penghimpunan dana zakat di Indonesia. Selain itu, dapat memudahkan masyarakat yang ada di setiap wilayah Indonesia untuk memberikan zakatnya kepada OPZ.

Dari sekian banyaknya OPZ yang ada di Indonesia, di antaranya adalah Dompet Dhuafa (DD), Rumah Zakat (RZ), Badan Amil Zakat Nasional (BAZNAS pusat), PKPU, dan DPU-DT. Tabel 1 menunjukan data yang dapat dilihat dari laporan penerimaan keuangan dana zakat lembagalembaga pengelola zakat yang ada.

Tabel 1. Laporan Keuangan Lembaga

\begin{tabular}{lllll}
\multicolumn{5}{c}{ pengelola Zakat } \\
\hline Nama LPZ & $\begin{array}{l}2010 \\
\text { (Milyar } \\
\text { Rupiah) }\end{array}$ & $\begin{array}{l}2011 \\
\text { (Milyar } \\
\text { Rupiah) }\end{array}$ & $\begin{array}{l}\text { (Milyar } \\
\text { Rupiah) }\end{array}$ & $\begin{array}{l}\text { (Milyar } \\
\text { Rupiah) }\end{array}$ \\
\hline PKPU & 21,2 & 25,6 & 35,7 & 39,5 \\
DD & 60,6 & 75,5 & 98,2 & 124,3 \\
RZ & 56,7 & 61,1 & 82,5 & 77,7 \\
BAZNAS & 22,7 & 32,3 & 40,3 & 50,7 \\
pusat & & & & \\
DPUDT & 9,8 & 12,2 & 17,3 & 24,5 \\
Jumlah & 114,2 & 211,8 & 274 & 316,7 \\
\hline Sumber: & Laporan Keuangan Zakat Tahun 2010- \\
\multicolumn{5}{l}{ 2013 }
\end{tabular}

Perkembangan penerimaan dana zakat di Indonesia. Berdasarkan tabel tersebut, DD menempati posisi pertama dalam hal penghimpunan dana zakat, dari potensi dana zakat yang ada DD hanya menarik sebesar 0,06\%. Dan yang menduduki peringkat kedua adalah Rumah Zakat, dimana penghimpunan dana zakatnya di tahun 2013 sebesar Rp 77,7 milyar setara dengan 0,03\% dari potensi zakat yang ada. Sementara itu, di posisi ketiga ditempati oleh BAZNAS dengan perolehan dana zakat sebesar Rp 50,7 milyar atau setara dengan 0,02 persen dari potensi zakat yang ada. Dan di bawah BAZNAS pusat adalah PKPU yang hanya mengumpulkan dana zakat sebesar Rp 39,5 Milyar di tahun 2013 bila dipersenkan dengan potensi zakat di Indonesia, maka hanya sebesar 0,01 persen. DPU-DT mampu mengumpulkan dana zakat sebesar Rp. 24,5 milyar setara dengan 0,01 persen, meski tergolong angka yang kecil bila dibandingkan dengan lembaga yang lain. Namun ini merupakan persentasi tersendiri bagi DPU-DT, karena mampu meningkatkan pengumpulan dana zakat sebesar 7,2 milyar dari tahun sebelumnya yang hanya sebesar Rp. 17,3 milyar rupiah.

Jika OPZ menginginkan muzaki lebih banyak untuk mengeluarkan dana zakatnya kepada OPZ, maka OPZ membutuhkan strategi untuk mengoptimalkan penarikan dana zakatnya dari masyarakat di Indonesia. Selain itu, OPZ juga perlu melakukan evaluasi terhadap metode pengumpulan dana zakat yang telah dilakukan selama ini.

\section{MATERI DAN METODE}

Penelitian yang dilakukan menggunakan jenis penelitian analisis deskriptif kuantitatif. Analisis deskriptif merupakan alat analisis yang menjadi pondasi bagi seluruh penelitian, sehingga dapat juga dilakukan melalui kuantitatif agar memudahkan analisis statistik.

Dalam penelitian ini, yang menjadi populasi adalah OPZ yang berada di Indonesia. Populasi membutuhkan sampel untuk memudahkan dalam penelitian. Karena sampel hanya mengambil sebagian 
dari jumlah populasi yang telah ditetapkan dan dapat juga mewakili dari keseluruhan populasi. Sampel penelitian yang digunakan adalah lima OPZ di Indonesia yaitu: BAZNAS, DD, RZ, PKPU, dan DPU-DT.

Data penelitian ini diperoleh melalui interview dan pengisian kuesioner yang diberikan kepada lima lembaga pengelola zakat. Untuk menunjang data penelitian agar semakin tepat dan akurat, maka diperlukan data sekunder yang dapat memperkuat informasi yang didapatkan dari data primer, baik wawancara ataupun kuesioner. Data sekunder berasal dari laporan keuangan OPZ.

Teknik penghimpunan data dalam penelitian ini menggunakan dua metode, yaitu: kuesioner merupakan teknik pengumpulan informasi yang memungkinkan analis memahami sikap atau perilaku, keyakinan, dan karakteristik objek atau beberapa orang yang menjadi sumber pokok dalam suatu organisasi, dimana objek tersebut terpengaruh oleh aturan yang diusulkan atau yang telah berjalan.

Metode kedua yang digunakan adalah wawancara merupakan metode pengumpulan data dalam memperoleh keterangan atau jawaban dari proses penelitian yang dihasilkan melalui tanya jawab dengan bertatap muka secara langsung dengan responden dan dapat diperoleh melalui alat yang disebut interview guide (panduan wawancara). Tujuan penulis menggunakan teknik ini, untuk mendapatkan informasi atau data secara jelas dan konkret tentang strategi yang digunakan oleh ke lima OPZ.

Setelah data yang diperoleh dari lapangan telah terkumpul, maka selanjutnya peneliti akan mengolah dan menganalisis data tersebut dengan menggunakan analisis spyderweb.

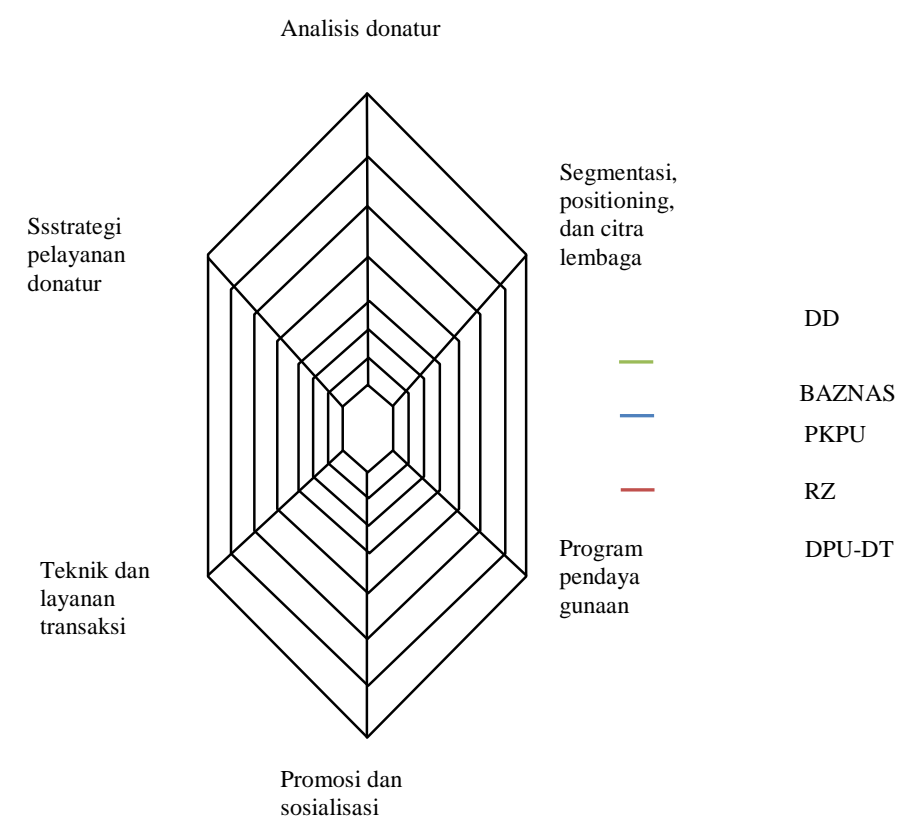

Gambar 1. Grafik Syderweb

Kegiatan pertama dilakukan QDA untuk mendiskripsikan sampel yang sudah dipilih dari populasi yang ada. Cara mendiskripsikan sampel yaitu dengan memberikan pertanyaan wawancara dari masing-masing sampel dan memberikan pertanyaan kuisioner kepada populasi yang ada pada masing-masing sampel tersebut.

Setelah data terkumpul, maka pengujian ini akan dibantu dengan menggunakan grafik spyderweb dengan nilai nol pada titik pusat untuk setiap sampel. Menurut Ernawaty dan Putri (2014:184) Kelemahan dari analisis syderweb ini adalah analis harus mampu untuk menerjemahkan berbagai indikator yang sifatnya kualitatif menjadi kuantitatif agar dapat digambar dalam syderweb. Garis standar harus disusun dengan jumlah maksimal yang sama agar tidak terjadi bias saat mengukur gap. 


\section{HASIL DAN PEMBAHASAN}

\section{Penghimpunan Dana Zakat}

\section{BAZNAS pusat}

Penghimpunan dana zakat di BAZNAS pusat pada tahun 2010-2011 meningkat sebesar 42\%, namun persentase peningkatannya menurun di tahun selanjutnya yakni menjadi sebesar $24 \%$. Dan meningkat kembali di tahun 20122013 sebesar 25\%. BAZNAS pusat dalam penghimpunan dana zakatnya selalu meningkat secara stabil.

Tabel 2. Laporan Keuangan BAZNAS Pusat

\begin{tabular}{llll}
\hline Tahun & Penghimpunan & Tahun & $\%$ \\
\hline 2010 & Rp. 22,7 milyar & & \\
2011 & Rp. 32,3 milyar & $2010-2011$ & $42 \%$ \\
2012 & Rp. 40,3 milyar & $2011-2012$ & $24 \%$ \\
2013 & Rp. 50,7 milyar & $2012-2013$ & $25 \%$ \\
\hline
\end{tabular}

Sumber: laporan keuangan tahunan BAZNAS pusat

Pada tahun 2010 juga BAZNAS pusat mengeluarkan biaya untuk sosialisasi dan layanan muzaki sebesar Rp. 3,07 milyar, namun dengan biaya sebesar itu BAZNAS pusat mampu mengumpulkan dana zakat dari para muzaki sebesar Rp. 22,7 milyar. Kemudian pengeluaran di tahun 2011 sebesar Rp. 3,08 milyar, dan menghimpun dana zakat dari masyarakat sebesar $\mathrm{Rp}$. 32,3 milyar.

\section{Tabel 3. Laporan Biaya Promosi dan Sosialisasi}

\begin{tabular}{clcc}
\hline Tahun & Pengeluaran & Tahun & $\%$ \\
\hline 2010 & Rp. 3,07 milyar & \\
2011 & Rp. 3,08 milyar & 2010-2011 & $0,08 \%$ \\
\hline \multicolumn{4}{l}{ Sumber: laporan keuangan tahunan BAZNAS pusat }
\end{tabular}

Pengeluaran BAZNAS pusat untuk biaya sosialisasi dan layanan muzaki, di tahun 2010-2011 meningkat sebesar Rp. 2.5 juta setara dengan $0,08 \%$. Dan di tahun tersebut, perolehan penghimpunan dana zakat dari biaya yang dikeluarkan untuk sosialisasi dan layanan muzaki sebesar Rp. 22,7 milyar setara dengan $42 \%$.

Pada tahun 2011, BAZNAS pusat mengeluarkan anggaran untuk beban publikasi dan dokumentasi dengan biaya sebesar Rp. 1,94 milyar, dengan biaya sebesar itu BAZNAS pusat mampu mendapatkan dana zakat sebesar Rp. 22,7 milyar. Kemudian di tahun 2012 sebesar Rp. 1,96 milyar, dan dapat memperoleh dana zakat sebesar Rp. 32,3 milyar. Selanjutnya di tahun 2013 mengeluarkan dana lebih kecil dari tahun sebelumnya hanya dengan sebesar 1,45 milyar, dan mengumpulkan dana zakat dari masyarakat sebesar Rp. 40,3 milyar.

Tabel 4. Laporan Beban Publikasi dan Dokumentasi

\begin{tabular}{llll}
\hline Tahun & Pengeluaran & Tahun & $\%$ \\
\hline 2011 & Rp. 1,94 milyar & & \\
2012 & Rp. 1,96 milyar & $2011-2012$ & $1,18 \%$ \\
2013 & Rp. 1,45 milyar & $2012-2013$ & $-35 \%$ \\
\hline
\end{tabular}

Sumber: laporan keuangan tahunan BAZNAS pusat.

Pengeluaran BAZNAS pusat untuk beban publikasi dan dokumentasi, di tahun 2011-2012 meningkatkan dananya sebesar Rp. 23.3 juta setara dengan 1,18\%. Dan di tahun 2012-2013 menurunkan dananya sebesarnya Rp. - 515,2 juta setara dengan -35\%. Meski demikian penurunan jumlah publikasi dan dokumentasi yang dilakukan BAZNAS tidak serta merta menurunkan jumlah penerimaan zakat pada tahun 2013 . Perolehan dana zakat pada tahun 2013 justru mengalami peningkatan.

BAZNAS pusat menghimpun dana zakat dari muzaki entitas di tahun 2010 sebesar Rp. 2,1 milyar, tetapi menghimpun dana zakat dari muzaki individual sebesar Rp. 38,4 milyar. Di tahun 2012 muzaki entitas yang memberikan zakat kepada BAZNAS pusat menurut hanya sebesar Rp. 
1,6 milyar, dan muzaki individual pun hanya sebesar Rp. 30,2 milyar. Tetapi di tahun 2013 penghimpunan dana zakat dari muzaki entitas mengalami peningkatan sebesar Rp. 3 milyar, dan dari muzaki individualnya pun meningkat tinggi sebesar Rp. 47 milyar. Visi misi BAZNAS untuk memberikan kesadaran kepada masyarakat untuk membayar zakat bisa dibilang tercapai. Karena kebanyakan penghimpunan zakat berasal dari muzaki individual. Sehingga muzaki individual benar-benar sudah sadar dan peduli terhadap pentingnya untuk membayar zakat.

BAZNAS pusat menghimpun dana zakat dari muzaki entitas di tahun 2011 hanya $6,5 \%$ dari total penerimaan dana zakat muzaki, sementara penghimpunan dana zakat dari muzaki individual sebesar 93,5\% dari total penerimaan dana zakat muzaki. Penghimpunan di tahun 2012 dana zakat yang diterima oleh muzaki entitas hanya $4 \%$ menurun dari tahun sebelumnya yang menghimpun 6,5\%, sedangkan dana zakat yang diterima oleh muzaki individual sebesar 96\% meningkat dari tahun sebelumnya yang hanya menerima sebesar 93,5\% saja. Di tahun selanjutnya yaitu tahun 2013 penerimaan dana zakat dari muzaki entitas meningkat kembali sebesar $6 \%$, dan penerimaan dana zakat dari muzaki individual menurun kembali menjadi $94 \%$.

Berdasarkan data tersebut dapat dilihat bahwa muzaki individu tetap menjadi sumber perolehan pengumpulan dana zakat yang tinggi bagi BAZNAS. Meskipun demikian muzaki entitas tetap memberikan kontribusi yang signifikan. Jika dibandingkan antara jumlah pemberi zakat individu dengan muzaki entitas meskipun secara kuantitas jumlah penerimaan lebih besar, namun secara kinerja membutuhkan etos kerja yang besar pula karena dana tersebut dikumpulkan dari jumlah masyarakat yang sangat banyak. Namun, pada muzaki entitas jumlah penerimaan zakat tersebut diterima dari beberapa entitas saja, sehingga diperlukan peningkatan target dan sasaran untuk memperluas jangkauan muzaki entitas.

\section{Dompet Dhuafa}

Dompet Dhuafa menghimpun dana zakat di tahun 2010 sebesar Rp. 60,6 milyar dan meningkat di tahun 2011 sebesar Rp. 75,5 milyar. Di tahun 2012 Dompet Dhuafa menghimpun dana zakat sebesar Rp. 98,2 milyar, dan di tahun 2013 meningkat tinggi hingga mencapai Rp. 124,3 milyar.

Tabel 5. Laporan Keuangan Dompet Dhuafa

\begin{tabular}{llll}
\hline Tahun & Penghimpunan & Tahun & $\%$ \\
\hline 2010 & Rp. 60,6 milyar & & \\
2011 & Rp. 75,5 milyar & $2010-2011$ & $80 \%$ \\
2012 & Rp. 98,2 milyar & $2011-2012$ & $76 \%$ \\
2013 & Rp. 124,3 milyar & $2012-2013$ & $79 \%$ \\
\hline
\end{tabular}

Sumber: laporan keuangan tahunan Dompet Dhuafa

Persentase penghimpunan dana zakat Dompet Dhuafa tahun 2010-2011 sebesar 24 persen, dan meningkat di tahun 20112012 sebesar 30 persen, namun di tahun 2012-2013 ternyata menurun sebesar 26 persen.

Dompet Dhuafa mengeluarkan dana untuk biaya sosialisasi ZISWAF di tahun 2010 sebesar Rp. 8,8 milyar, dengan biaya sebesar itu Dompet Dhuafa dapat menghimpun dana zakat dari masyarakat sebesar Rp. 60,6 milyar. Kemudian di tahun 2011 mengeluarkan dana lebih besar sebanyak Rp. 14,5 milyar, dan menghimpun dana zakat dari masyarakat sebesar Rp. 75,5 milyar. Dan selanjutnya di 
tahun 2012 mengeluarkan dana sebesar 16,2 milyar, dan menghimpun dana zakat dari masyarakat sebesar Rp. 98,2 milyar. Dan terakhir di tahun 2013 mengeluarkan dana lebih besar sebanyak Rp. 20,5 milyar, dan menghimpun dana zakat dari masyarakat sebesar Rp. 124,3 milyar.

\section{Tabel 6. Laporan Biaya Sosialisasi ZISWAF}

\begin{tabular}{llll}
\hline Tahun & Pengeluaran & Tahun & $\%$ \\
\hline 2010 & Rp. 8,8 milyar & & \\
2011 & Rp. 14,5 milyar & $2010-2011$ & $39 \%$ \\
2012 & Rp. 16,2 milyar & $2011-2012$ & $10 \%$ \\
2013 & Rp. 20,5 milyar & $2012-2013$ & $20 \%$ \\
\cline { 1 - 3 }
\end{tabular}

Sumber: laporan keuangan tahunan BAZNAS pusat

Pengeluaran Dompet Dhuafa untuk biaya sosialisasi ZISWAF di tahun 20102011 meningkatkan dananya sebesar Rp. 5,7 milyar setara dengan 39 persen. Dan di tahun 2011-2012 meningkat, namun tidak sebesar tahun sebelumnya hanya sebesarnya Rp. 1,7 milyar setara dengan 10 persen. Kemudian di tahun 2012-2013 meningkatkan dananya sebesar Rp. 4,3 milyar setara dengan 20 persen.

Peningkatan jumlah biaya sosialisasi yang dilakukan oleh Dompet Dhuafa, memberikan dampak positif terhadap peningkatan jumlah penerimaan dana zakat Dompet Dhuafa. Peningkatan jumlah biaya sosialisasi pada tahun 2010 ketahun 2011 sebesar 5,7 miliar memberikan dampak kenaikan jumlah penerimaan dana zakat sebesar 14.9 miliar. Kenaikan biaya sosialisasi tersebut mampu meningkatkan 2,6 dari biaya sosialisasi yang dikeluarkan. Hal ini menunjukan bahwa peningkatan biaya sosialisasi tersebut efektif dilakukan dalam peningkatan jumlah penerimaan dana zakat.

\section{Pos Keadilan Peduli Umat}

Penghimpunan PKPU di tahun 2010 sebesar Rp. 21,2 milyar dan di tahun 2011 meningkat sebesar Rp. 4,4 milyar sehingga menjadi Rp. 25,6 milyar. Di tahun 2012 penghimpunan PKPU sebesar Rp. 35,7 milyar, kemudian meningkat di tahun 2013 sebesar Rp. 39,5 milyar. PKPU mengalami peningkatan setiap tahunnya, namun tidak terlalu besar meningkatnya.

Tabel 7. Laporan Keuangan PKPU

\begin{tabular}{llll}
\hline Tahun & Penghimpunan & Tahun & $\%$ \\
\hline 2010 & Rp. 21,2 milyar & & \\
2011 & Rp. 25,6 milyar & $2010-2011$ & $20 \%$ \\
2012 & Rp. 35,7 milyar & $2011-2012$ & $39 \%$ \\
2013 & Rp. 39,5 milyar & $2012-2013$ & $10 \%$ \\
\hline
\end{tabular}

Sumber : laporan keuangan tahunan PKPU

Persentase penghimpunan PKPU di tahun 2010-2011 sebesar 20 persen, meningkat di tahun selanjutnya tahun 2011-2012 sebesar 39 persen. Namun di tahun selanjutnya yakni tahun 2012-2013 hanya sebesar 10 persen.

\section{Rumah Zakat}

Rumah zakat menghimpun dana zakat di tahun 2011 sebesar Rp. 61,1 milyar, dan meningkat cukup drastis di tahun selanjutnya yaitu tahun 2012 sebesar Rp. 82,5 milyar. Kemudian di tahun 2013 mengalami penurunan yang lumayan cukup besar, yaitu di tahun 2013 sebesar Rp. 77,7 milyar. Penurunan yang sangat drastis di tahun 2013 tersebut, menjadikan lembaga rumah zakat harus memikirkan strategi penghimpunan yang baru dengan baik dan bagus. Sehingga bisa menghimpun dana zakat lebih besar lagi.

Tabel 8. Laporan Keuangan Rumah Zakat

\begin{tabular}{llll}
\hline Tahun & Penghimpunan & Tahun & $\%$ \\
\hline 2010 & Rp. 56,7 milyar & & \\
2011 & Rp. 61,1 milyar & $2010-2011$ & $16 \%$ \\
2012 & Rp. 82,5 milyar & $2011-2012$ & $35 \%$ \\
2013 & Rp. 77,7 milyar & $2012-2013$ & $-18 \%$ \\
\hline \multicolumn{2}{l}{ Sumber $:$ annual report RZ 2013 }
\end{tabular}

Persentase penghimpunan rumah zakat pada tahun 2010-2011 meningkat 
sebesar 16 persen, dan meningkat lagi di tahun 2011-2012 sebesar 35 persen. Namun di tahun 2012-2013 mengalami penurunan yang sangat drastis, yakni sebesar -18 persen. Rumah Zakat mengeluarkan biaya untuk iklan dan marketing di tahun 2012 sebesar Rp. 5,4 milyar, kemudian pengeluaran di tahun 2013 sebesar Rp. 6,8 milyar.

Tabel 9. Laporan Beban Iklan dan Marketing

\begin{tabular}{llll}
\hline Tahun & Pengeluaran & Tahun & $\%$ \\
\hline 2012 & Rp. 5,4 milyar & & \\
2013 & Rp. 6,8 milyar & 2012-2013 & $20 \%$ \\
\hline
\end{tabular}

Sumber: Annual Report RZ 2013

Pengeluaran RZ untuk beban iklan dan pemasaran di tahun 2012-2012 sebesar Rp. 1,4 milyar setara dengan 20 persen, namun dana zakat yang terhimpun dari masyarakat malah menurun cukup drastis sebesar Rp. 77,7 milyar. Rumah Zakat memiliki jumlah donatur pada tahun 2010 sebanyak 84.379 jiwa. Dan meningkat pada tahun 2011 sebanyak 99.248 orang, dan meningkat di tahun 2012 sebanyak 120.655 orang, dan di tahun 2013 jumlah donatur sebanyak 136.908 orang. setiap tahun lembaga Rumah Zakat memperoleh donatur terus meningkat.

Tabel 10. Laporan Jumlah Donatur RZ

\begin{tabular}{llll}
\hline Tahun & Jumlah Donatur & Tahun & $\%$ \\
\hline 2010 & 84.379 jiwa & & \\
2011 & 99.248 jiwa & $2010-2011$ & $14 \%$ \\
2012 & 120.665 jiwa & $2011-2012$ & $17 \%$ \\
2013 & 136.908 jiwa & $2012-2013$ & $11 \%$ \\
\hline
\end{tabular}

Sumber: Laporan Keuangan Tahunan Rumah Zakat

Persentase jumlah donatur rumah zakat mengalami peningkatan yang stabil, pada tahun 2010-2011 juma donatur di RZ meningkat sebanyak 14.869 jiwa. Dan meningkat lagi pada tahun 2011-2012 jumlah donatur di RZ meningkat sebanyak 21.417 jiwa atau setara dengan 17 persen dari tahun sebelumnya. Kemudian meningkat kembali di tahun 2012-2013 sebanyak 16.243 jiwa atau setara dengan 11 persen dari tahun sebelumnya. Selama beberapa tahun terakhir. Jumlah yang paling banyak donaturnya adalah donatur corporate 99 persen sedangkan jumlah donatur retail hanya 1 persen.

\section{Dompet Peduli Umat Darut Tauhiid}

Dompet peduli umat darut tauhiid (DPU-DT) menghimpun dana zakat di tahun 2010 sebesar Rp. 9,8 milyar, dan meningkat di tahun 2011 sebesar Rp. 12,2 milyar. Kemudian di tahun 202 menghimpun dana zakat sebesar Rp. 17,3 milyar dan meningkat lagi di tahun 2013 sebesar Rp. 24,5 milyar.

\section{Tabel 11. Laporan Keuangan DPUDT}

\begin{tabular}{llll}
\hline Tahun & Penghimpunan & Tahun & $\%$ \\
\hline 2010 & Rp. 9,8 milyar & & \\
2011 & Rp. 12,2 milyar & $2010-2011$ & $24 \%$ \\
2012 & Rp. 17,3 milyar & $2011-2012$ & $42 \%$ \\
2013 & Rp. 24,5 milyar & $2012-2013$ & $41 \%$ \\
\hline
\end{tabular}

Sumber: laporan keuangan tahunan DPUDT

Penghimpunan yang dilakukan DPUDT di tahun 2010-2011 sebesar 24 persen, dan meningkat di tahun 2011-2012 sebesar 42 persen. Namun di tahun selanjutnya tahun 2012-2013 peningkatannya menurun sebesar 0,1 persen yaitu 41 persen meski demikian, DPU-DT mengalami peningkatan yang cukup stabil.

Penghimpunan dana zakat yang dilakukan oleh DPU-DT tergolong masih sedikit dibandingkan dengan lembagalembaga pengelola zakat yang lainnya. Karena DPU-DT tergolong masih lembaga zakat yang masih baru. Baru menjadi lembaga zakat nasional di tahun 2014. Namun walaupun tergolong lembaga zakat yang masih baru. DPU-DT bisa menghimpun dana zakat yang begitu besar hingga mencapai milyaran rupiah. 


\section{Metode Penghimpunan Dana Zakat}

Menurut Ernawaty dan Putri (2014:183) Spyder web atau radar chart sebenarnya telah banyak digunakan di berbagai industri untuk menerangkan ukuran kesenjangan (gap) antara kinerja faktual dengan standar kinerja. Kesenjangan yang terpotret dalam Spyder web menunjukkan indikator ekuitas mana yang belum terpenuhi serta seberapa besar kesenjangan tersebut belum terpenuhi. Penggunaan alat analisis Spyder web dalam penelitian ini adalah untuk mengukur optimalisasi antara strategi penghimpunan dana zakat yang dilakukan oleh ke lima LPZ tersebut.

Analisis profil donatur di BAZNAS pusat, yaitu mendata calon donatur dengan cara memberikan beberapa pertanyaan yang ada di formulir registrasi muzaki. Dengan melengkapi persyaratan sebagai berikut: nama, NIK (no KTP), alamat, no handphone, e-mail. Adapun informasi tambahan bagi calon donatur sebagai berikut: no telp, no rekening bank, atas nama no rekening, dan cabang bank no rekening. Data-data tersebut dibutuhkan BAZNAS pusat untuk data base lembaga, yang berguna untuk memberikan informasi kepada muzaki tentang laporan dana zakat yang disalurkan dan undangan apabila BAZNAS pusat mengadakan kegiatan yang melibatkan muzaki dan donatur potensial. Untuk analisis harapan donatur, BAZNAS pusat memiliki konsultasi online dengan Prof. Dr. K.H. Didin Hafidhuddin, M.Sc. yang ada di website BAZNAS pusat, muzaki atau calon muzaki bias menanyakan pertanyaan, keluhan, dan masukan kepada BAZNAS pusat di website.

Segmentasi penghimpunan dana di BAZNAS pusat berskala lokal, seperti daerah Jakarta pusat dan sekitarnya.
Namun tidak menutup kemungkinan, BAZNAS pusat menghimpun dana dari luar daerah Jakarta, seperti Indonesia dan luar negeri. Karena BAZNAS pusat mewakili badan amil zakat nasional di Indonesia, untuk nasional sudah ada BAZNAS provinsi dan BAZNAS daerah (kota/kabupaten) yang tersebar di seluruh Indonesia.

Berdasarkan wawancara yang dilakukan dengan BAZNAS pusat (31 juli 2015) pencitraan lembaga menurut BAZNAS pusat tidak terlalu penting, karena BAZNAS pusat menginginkan muzaki yang membayarkan zakat ke BAZNAS pusat berasal dari kesadaran muzaki itu sendiri. BAZNAS pusat menyandang, apabila muzaki membayar zakat karena citra lembaga. Maka ketika citra lembaga tersebut jatuh/jelek, meski kemungkinan muzaki tersebut akan berpindah membayar zakatnya ke lembaga zakat yang lain.

Meskipun BAZNAS pusat memilih pencitraan tidak terlalu penting, pada kenyataannya BAZNAS tetap melakukan teknik-teknik pencitraan seperti lembaga lain. Contohnya menggunakan tokoh seperti Didin Hafiduddin ketua BAZNAS yang ada di dalam iklan website, iklan di baliho, dan iklan di televisi. hal tersebut yang dilakukan pun bisa meningkatkan citra lembaga kepada para masyarakat di Indonesia.

Program pendayagunaan di BAZNAS pusat memiliki satu keunggulan, yaitu BAZNAS pusat bekerja sama dengan stasiun televisi trans $7 \mathrm{di}$ acara program orang pinggiran. Dimana salah satu pengalokasian dananya diberikan kepada orang yang kurang mampu dalam kebutuhan sehari-hari. Program ini pun bisa dijadikan program promosi kepada donatur potensial yang melihat program 
acara tersebut, sehingga acara tersebut bisa juga dijadikan metode promosi dan sosialisasi bagi masyarakat Indonesia.

Metode promosi dan sosialisasi yang dilakukan oleh BAZNAS pusat hanya menggunakan satu metode fundraising, yaitu metode fundraising tidak langsung. Yang menyelenggarakan kegiatan yang melibatkan donatur potensial dan muzaki yang telah terdaftar di BAZNAS pusat. Promosi yang dilakukan BAZNAS pusat bermacam-macam, seperti: memasang baliho, memasang iklan di internet, memasang iklan di televisi, dan juga promosi di acara tertentu. Adapun sosialisasi yang dilakukan oleh BAZNAS pusat, contohnya sebagai berikut: bersilaturahmi ke perusahaan-perusahaan besar, melakukan sosialisasi mabes polri, melakukan sosilisasi di iklan-iklan seperti, di baliho, di internet, dan di media elektonik maupun cetak.

Teknik layanan transaksi donasi yang dilakukan oleh BAZNAS pusat, melalui ATM terdapat vasilitas bayar zakat yang langsung menunjukan pembayaran zakat tersebut ke BAZNAS, Online terdapat formulir pembayaran zakat, Muzaki corner adalah aplikasi yang terdapat di android dan iphone, dan Jemput zakat.

Strategi pelayanan donatur yang dilakukan oleh BAZNAS pusat menggunakan dua strategi pelayanan, yaitu untuk donatur potensial dan donatur non potensial. Pelayanan donatur biasa yang dilakukan oleh BAZNAS dengan cara diberikan laporan setiap bulan dalam bentuk news letter, diingatkan supaya menunaikan zakatnya setiap 1 bulan sekali, diberikan laporan dalam bentuk majalah. Pelayanan donatur yang potensial dilakukan oleh BAZNAS dengan melakukan silaturahmi kepada donatur yang potensial,
Mengundang mereka ke acara yang dilakukan oleh BAZNAS pusat.

Tabel 12. Strategi Penghimpunan Dana Zakat BAZNAS Pusat

Faktor Penentu

Keberhasilan

Penghimpunan Tingkat

Dana Zakat Kepentingan Kenyataan

1. Analisis Profil dan Harapan

Donatur 44

2. Segmentasi,

Positioning,

dan Pencitraan $\quad 4,2 \quad 3,3$

3. Program

Pendayagunaa

n $4,3 \quad 4,3$

4. Metode

Promosi dan

$\begin{array}{lll}\text { Sosialisasi } & 3,7 & 3,7\end{array}$

5. Teknik

Layanan

Transaksi

Donasi $\quad 3,2 \quad 3,2$

6. Strategi

Pelayanan

Donatur $\quad 4,3 \quad 4,3$

Dari nilai-nilai tersebut akan digambarkan dengan gambar 2 .

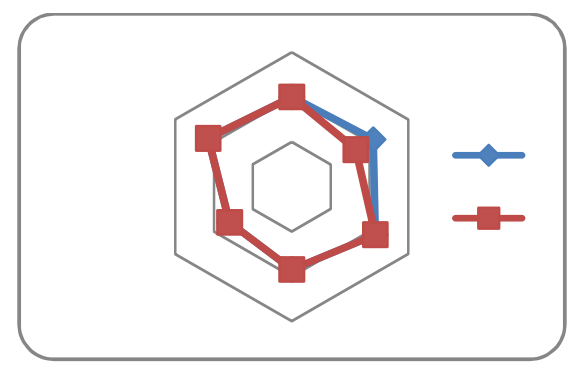

Gambar 2. Grafik Spyderweb BAZNAS Pusat

Untuk garis yang berwarna merah dalam grafik 2 . adalah garis kenyataan, dan untuk garis biru adalah tingkat kepentingan. Menurut BAZNAS pusat, tingkat kepentingan dan kenyataan yang paling tinggi adalah di program pendayagunaan dan strategi pelayanan donatur. Bagi BAZNAS pusat dana yang terhimpun harus sesegera mungkin 
disalurkan kepada program pendayagunaan, karena apabila melebihi satu tahun uang yang tidak disalurkan maka bagi BAZNAS pusat adalah dzalim. Untuk nilai yang paling rendah adalah teknik layanan transaksi donasi, karena BAZNAS pusat tidak terlalu terkosentrasi pada layanan muzaki. BAZNAS pusat sudah memiliki aplikasi muzaki corner, dimana aplikasi tersebut membantu muzaki untuk mengetahui tentang BAZNAS pusat dan melakukan transaksi donasi di aplikasi tersebut secara online.

Analisis profil donatur di Dompet Dhuafa, yaitu dengan cara memberikan beberapa pertanyaan yang ada di dalam formulir registrasi donatur Dompet Dhuafa. Dengan pertanyaan sebagai berikut: nama lengkap, nama publikasi, tempat lahir, tanggal lahir, e-mail, NPWP, jenis kelamin, pendidikan, pekerjaan, no identitas (no KTP), no HP, alamat rumah lengkap, no telephone rumah, no fax rumah, kantor, alamat lengkap kantor, telephone kantor, dan fax kantor. Data tersebut digunakan untuk membaginya ke dalam kelas donatur seperti apakah mereka itu, apakah donatur tersebut potensial atau donatur biasa. Sehingga bisa dianalisis untuk prospek ke depannya.

Analisis harapan donatur yang dilakukan Dompet Dhuafa melalui masukan-masukan dari muzaki yang ditulis melalui keluhan donatur yang ada di layanan donatur dalam website Dompet Dhuafa. Layanan keluhan donatur tersebut bisa di analisis oleh lembaga, apa saja yang dikeluhkan muzaki dan yang diharapkan muzaki terhadap pelayanan donatur yang diinginkan.

Segmentasi penghimpunan Dompet Dhuafa yaitu internasional, karena Dompet Dhuafa tidak menghimpun dana zakat di
Indonesia saja melainkan dari luar negeri. Sehingga tidak menutup kemungkinan untuk Dompet Dhuafa membuka cabang di Negara-negara lain, seperti: Australia, Japan, Korea Selatan, Amerika, dan Hongkong.

Positioning Dompet Dhuafa dalam hal penghimpunan menempati peringkat pertama bila di bandingkan dengan lembaga-lembaga zakat lain yang ada di Indonesia. Dilihat dari data penghimpunan setiap lembaga zakat yang ada di Indonesia. Untuk meningkatkan citra lembaga, Dompet Dhuafa melalui program-program pendayagunaan, yaitu: program pendidikan, ekonomi, kesehatan, sosial, dan kawasan terpadu. Kepercayaan donatur atas dana zakat yang telah mereka salurkan. Hal ini dananya, disalurkan di Dompet Dhuafa dan bagaimana manfaat bagi mustahik dari dana yang disalurkannya. Selain itu, Dompet Dhuafa pun menggunakan beberapa tokoh ternama untuk meningkatkan citra lembaga kepada masyarakat. Program pendayagunaan di Dompet Dhuafa yaitu: program pendidikan (Bebas Biaya Sekolah, Sekolah Mandiri, dan Pendidikan (In-Non Formal), ekonomi (perternakan, Pertanian, UMKM dan Industri Kreatif, LKMS, dan Institut Kemandirian), kesehatan (Layanan Kesehatan Cuma-cuma dan Rumah Sehat Terpadu), sosial (Pengelolaan Bencana, Advokasi Buruh Migran, Program Tematik, Corp Dai Dompet Dhuafa, Layanan Jenazah Gratis, dan Dompet Dhuafa Volunteer), dan Kawasan Terpadu. Apabila program pendayagunaan tercapai dengan hasil yang baik, maka akan menciptakan pencitraan yang baik kepada muzaki.

Dompet Dhuafa menggunakan metode fundarising langsung dan tidak langsung, cara promosi fundraising yang dilakukan 
Dompet Dhuafa sama dengan perusahaan nirlaba yang lain. Seperti menggunakan program ATL (above the line) yaitu komunikasi melalui media massa sebagai sarana mempromosikan brand atau merk berbasis media elektronik, atau biasa disebut dengan serangan udara, contohnya seperti: menyelenggarakan kegiatan, membuat majalah. Iklan di TV, radio, koran, dan media sosial. BTL (below the line) yaitu teknik periklanan yang lebih spesifik dalam memasarkan produk atau layanannya yang dapat berupa aktivitas yang berhubungan atau berinteraksi secara langsung dengan donatur atau biasa disebut dengan melalui serangan darat, contohnya seperti: kanvasing, sebar brosur, telemarketing, direct mail, membuka counter, direct marketing, direct chanel. Untuk sosialisasi yang dilakukan Dompet Dhuafa yaitu memasang kata-kata tentang zakat dan citra lembaga yang baik di iklan, dan sesekali sering mengadakan sosialisasi ke daerah-daerah yang ada di Indonesia.

Teknik layanan transaksi donasi. Dompet Dhuafa memiliki beberapa strategi yang digunakan untuk teknik layanan transaksi seperti: direct channel contohnya memiliki kantor kas yang tersebar di wilayah yang ditentukan. In direct channel contohnya aktivitas banking channel, yaitu kemudahan muzaki untuk membayarkan zakat tidak perlu mengantri di bank. Dompet Dhuafa hampir bekerja sama dengan semua bank yang ada di Indonesia.

Strategi pelayanan donatur, Dompet Dhuafa memiliki program-program untuk melibatkan muzaki atas program pendayagunaan yang telah berhasil. Seperti: care visit donatur yaitu kunjungan donatur ke program-program Dompet Dhuafa, agar para muzaki bisa melihat langsung program-program Dompet
Dhuafa itu manfaatnya bagaimana dan seperti apa.

Tabel 13. Strategi Penghimpunan Dana Zakat Dompet Dhuafa

Faktor Penentu

Keberhasilan

Penghimpunan Tingkat

Dana Zakat Kepentingan Kenyataan

1. Analisis Profil

dan Harapan

Donatur $\quad 3.8$

2. Segmentasi,

Positioning, dan

$\begin{array}{lll}\text { Pencitraan } & 3.6 & 3.6\end{array}$

3. Program

Pendayagunaan

3.7

4. Metode Promosi dan Sosialisasi

5. Teknik Layanan

Transaksi Donasi

4

4

6. Strategi

Pelayanan

Donatur

$4 \quad 4$

Dari nilai-nilai tersebut akan digambarkan pada gambar 3 .

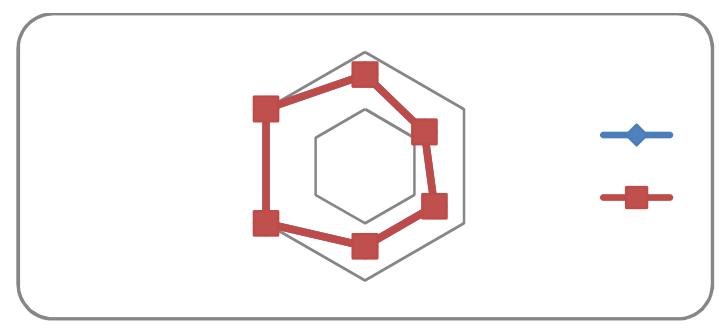

Gambar 3. Grafik Spyder web Dompet Dhuafa

Menurut Dompet Dhuafa, tingkat kepentingan dan kenyataan yang paling tinggi adalah di teknik layanan transaksi donasi dan strategi pelayanan donatur. Bagi Dompet Dhuafa teknik layanan transaksi donasi dan sstrategi pelayanan donatur penting, karena donatur akan mendonorkan dananya dengan melihat pelayanan yang dilakukan oleh sebuah 
lembaga zakat tersebut. Setelah memberikan teknik layanan transaksi donasi yang baik kepada donatur, maka seanjutnya lembaga harus memikirkan strategi pelayanan donatur kepada donatur tersebut. Apabila strategi pelayanan donatur itu gagal dilakukan, donatur tidak akan mendonorkan lagi dana zakat tersebut ke lembaga. Untuk nilai paling kecil pada grafik di atas adalah poin segmentasi, positioning, dan pencitraan, karena segmentasi Dompet Dhuafa sudah nasional bahkan memiliki kantor cabang di luar negeri.

Analisis profil donatur untuk PKPU, yaitu dengan melengkapi persyaratan sebagai berikut: user name (untuk data donatur PKPU), password (untuk masuk ke data donatur PKPU), e-mail, nama lengkap, cabang PKPU (dana zakat yang ingin dibayarkan), dan alamat lengkap. Dari pertanyaan yang diberikan kepada calon donatur di website tersebut, menunjukan bahwa PKPU memberikan pilihan pelayanan kepada donatur melalui cabang yang ditujunya. Sehingga PKPU benarbenar menganalisis calon donatur. Untuk analisis harapan donatur, PKPU belum melakukan analisa harapan yang diinginkan donatur tentang lembaga.

Segmentasi penghimpunan dana zakat yang dilakukan oleh PKPU berskala global/mendunia. Untuk dalam negeri lebih ke middle class muslim, karena masyarakat Indonesia paling banyak masyarakat muslim menengah atas. Sedangkan untuk luar negeri adalah komunitas TKI dan NGO luar.

Pencitraan lembaga yang dilakukan oleh PKPU yaitu memasang iklan-iklan seperti: baliho, internet, dan lain-lain. Hal tersebut dilakukan agar PKPU menjadi lembaga zakat yang terpercaya bagi umat.
Program pendayagunaan di PKPU yaitu, pendidikan (bea star, bea studi muda, sejuta, bedah sekolah, pelatihan guru inspiratif, dan M-life), ekonomi (gerobak mapan, KUMM, PIK, warung kaget), tanggap darurat (program CBDRM), kesehatan, sosial (pembangunan masjid, benah masjid dan mushola, pelatihan manajemen masjid, DAI, dan SAN), dan yatim (belanja bersama yatim dan wisata yatim).

Metode promosi dan sosialisasi yang dilakukan oleh PKPU adalah program promosi marketing multi dimensi baik langsung maupun tidak langsung, elektronik maupun cetak. Kedua metode digunakan oleh PKPU untuk segmentasi yang berbeda, untuk metode fundraising langsung mendatangi corporate atau muzaki potensial dan metode fundraising tidak langsung melalui promosi spanduk dan iklan website. Sosialisasi yang dilakukan oleh PKPU, sesekali mengadakan sosialisasi di tengah-tengah lingkungan masyarakat muslim.

Teknik layanan transaksi donasi yang dilakukan oleh PKPU yaitu dengan cara: setor langsung via counter atau gerai PKPU yang telah tersedia di setiap wilayah, transfer tunai ke bank, internet banking, dan atm zakat. Strategi pelayanan donatur di PKPU menggunakan cara Pendekatan personal untuk donatur potensial dengan memberikan nilai lebih kepada donatur potensial tersebut, nilai lebih tersebut adalah dengan memberikan pelayanan yang lebih dari yang lain. 
Tabel 14. Strategi Penghimpunan Dana Zakat PKPU

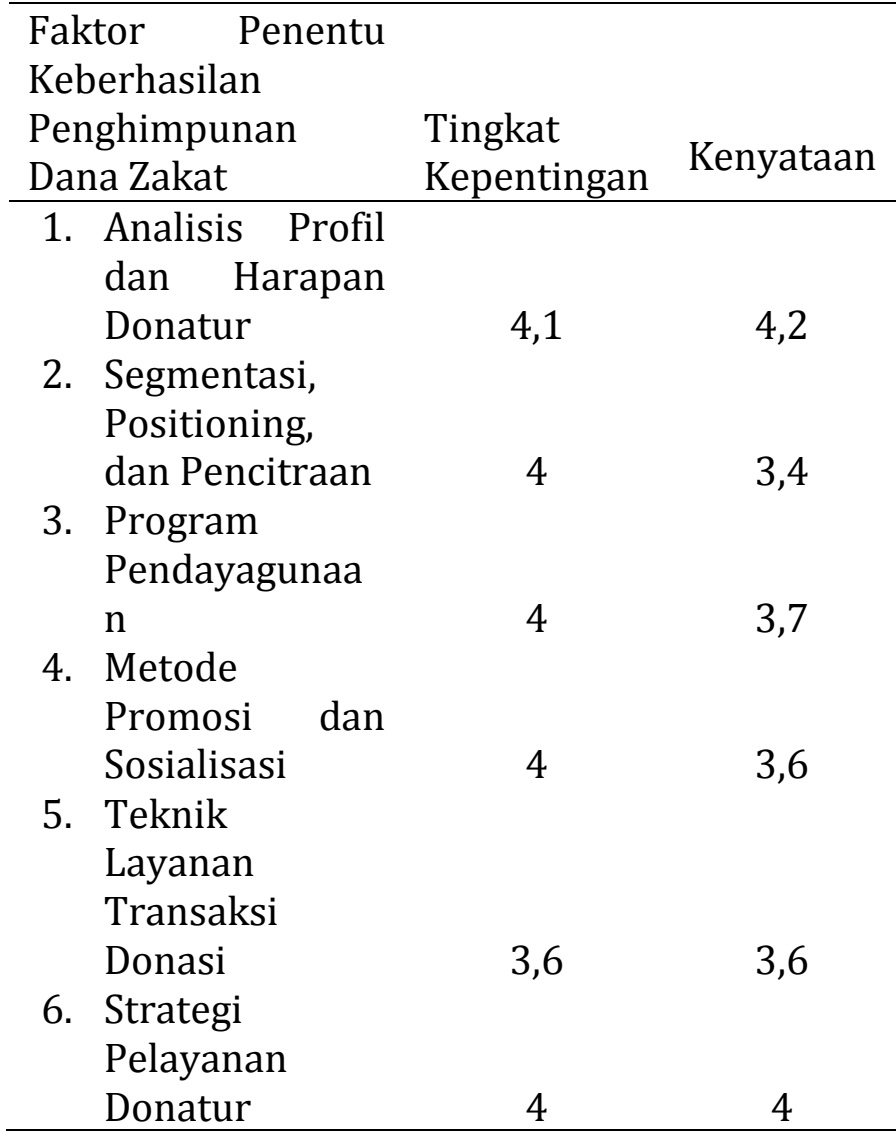

Syderweb dari nilai pada tabel 14. Digambarkan pada gambar 4.

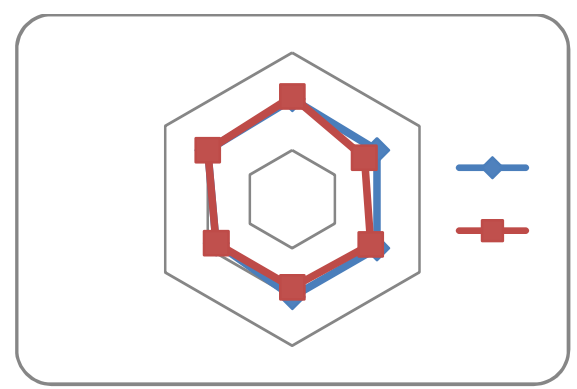

Gambar 4. Grafik spyderweb PKPU

Menurut PKPU, tingkat kepentingan dan kenyataan yang paling tinggi adalah di analisis profil dan harapan donatur, bagi PKPU status ekonomi calon donatur mempengaruhi profil dan harapan donatur untuk dipertimbangkan menjadi muzaki kelas atas atau muzaki kelas menengah. Kemudian untuk tingkat kepentingan yang paling rendah adalah teknik layanan transaksi donasi. Untuk nilai paling kecil pada garis kenyataan pada grafik di atas adalah poin segmentasi, positioning, dan pencitraan.

Analisis profil donatur di Rumah Zakat (RZ), yaitu dengan memberikan beberapa pertanyaan di formulir pendaftaran muzaki sebagai berikut: nama, e-mail, telephon, alamat, jumlah donasi, rincian donasi, program (zakat/infaq/shadaqoh), tujuan salur, jumlah, permintaan kornet, bank tujuan, pembayaran via (debet/ATM/setor tunai/e-banking/paypal), bank asal transfer, no rekening, tanggal transfer, bukti setor, kesediaan donasi. Dalam menganalisa calon donatur, lembaga rumah zakat lebih menanyakan pembayaran yang akan dilakukan oleh muzaki tersebut. Apakah akan memberikan zakatnya langsung atau lewat layanan transaksi yang ada di rumah zakat. Sehingga lembaga bisa menganalisa calon donatur itu kedalam kelas donatur seperti apa dan bagaimana, karena untuk melakukan pelayanan yang diberikan oleh RZ kepada donatur tersebut. Untuk analisis harapan donatur, RZ memberikan berbagai pilihan kontak kepada donatur. Apabila donatur mengeluh dan memberikan masukan kepada RZ.

Segmentasi penghimpunan dana zakat yang dilakukan oleh rumah zakat adalah berskala nasional. Pencitraan yang dilakukan oleh RZ sama saja dengan lembaga zakat lainnya, seperti: memasang iklan-iklan di media cetak maupun elektronik, Rumah Zakat Indonesia pun membranding dirinya menjadi Rumah Zakat lengkap dengan logo baru. Pencitraan lembaga dilakukan karena Rumah Zakat ingin menunjukkan kepada dunia sebuah lembaga non profit yang fokus di bidang filantropi dengan pengelolaan secara profesional layaknya perusahaan profit.

Untuk program pendayagunaan, RZ memiliki program unggulan yang diketahui 
oleh masyarakat muslim Indonesia, yaitu super qurban. Selain itu menyesuaikan dengan program-program reguler yang ada di rumah zakat. Seperti program rumpun seperti senyum sehat, senyum mandiri, senyum lestari, senyum juara, dan senyum ramadhan.Untuk lebih jelasnya bisa melihat langsung ke website RZ.

Metode promosi dan sosialisasi yang dilakukan oleh RZ adalah melalui iklan, media sosial, dan pengiriman kabar kepada donatur. RZ melakukan kedua metode fundraising tersebut.Untuk metode fundraising langsung yaitu kontak infak, dan metode fundraising tidak langsung yaitu melalui media sosial dan pengiriman kabar kepada donatur. Untuk promosi yang dilakukan RZ lebih menggunakan iklan di media sosial, karena biayanya yang tidak terlalu banyak dikeluarkan. Sosialisasi yang dilakukan oleh RZ lebih melakukan sosialisasinya di media internet, karena hampir semua orang mencari informasi lewat internet.

Teknik layanan donasi, RZ sudah banyak bekerja sama kepada banyak pihak untuk memudahkan donatur bertransaksi. Transaksi donasi yang sudah bisa dilakukan di RZ seperti atm, internet banking, paypal, kartu kredit, autodebet, host to host, virtual account, debet online, dan mobile banking.

Strategi pelayanan donatur, RZ menyesuaikan dengan kondisi donaturnya seperti apa yang akan dilayani sesuai dengan keinginan donatur. Baik melalui media yang sudah dicantumkan oleh donatur seperti WA, BB, atau yang lainnya. Semua donatur sudah memliki profil sendiri dimana pelayanannya, donatur yang akan menyesuaikan.
Tabel 15. Strategi Penghimpunan Dana Zakat Rumah Zakat

Faktor Penentu

Keberhasilan

Penghimpunan Tingkat

Dana Zakat

Kepentingan Kenyataan

1. Analisis Profil

dan Harapan

Donatur 4,5

2. Segmentasi,

Positioning, dan

Pencitraan

4,5

3. Program

Pendayagunaan

4. Metode Promosi dan Sosialisasi

5. Teknik Layanan

Transaksi Donasi

6. Strategi

Pelayanan

Donatur

4

4

Transformasi berdasarkan nilai tersebut dapat dilihat pada spyderweb gambar 5.

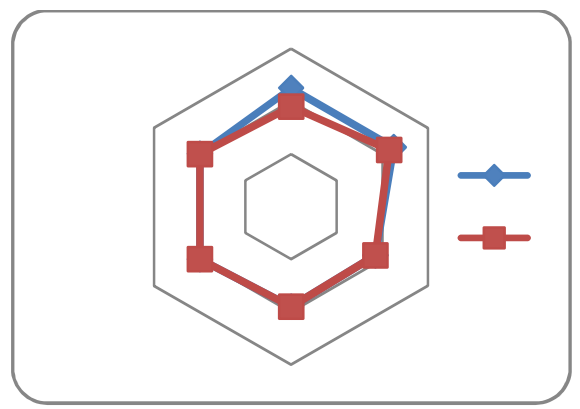

Gambar 5. Grafik spyderweb Rumah Zakat

Menurut Rumah Zakat, tingkat kepentingan yang paling tinggi adalah di analisis profil dan harapan donatur, bagi Rumah Zakat jenis kelamin, usia, dan status ekonomi calon donatur mempengaruhi profil muzaki. Kemudian untuk garis kenyataan pada grafik di atas yang paling tinggi adalah Segmentasi, positioning, dan pencitraan, bagi Rumah Zakat pencitraan lembaga itu penting agar masyarakat bisa memilih berdonasi ke lembaga zakat mana. 
Rumah Zakat ingin mengenalkan kepada masyarakat bahwa berdonasi di RZ itu mudah, cepat, efisien, tepat sasaran dan banak manfaat. Untuk nilai paling kecil pada garis tingkat kepentingan dan kenyataan adalah variabel Program Pendayagunaan, karena program RZ yang paling utama adalah program di bulan ramadhan dan Qurban. Sehingga masyarakat mengetahui program yang dilakukan oleh RZ hanya di bulan Ramadhan saja.

Analisis profil donatur di DPUDT, yaitu dengan memberikan pertanyaan di formulir registrasi donatur sebagai berikut: nama donatur, ID donatur, e-mail, telephone, jumlah donasi, tanggal pengiriman, no rekekning pengirim, nama pemilik rekening, bank, rekening tujuan, nomer validasi, dan pengiriman melalui (transfer bank/ATM/Internet banking/mobile banking). Analisis profil tersebut sangat diperlukan bagi DPUDT, karena untuk diklasifikasikan ke dalam bentuk segmen bagaimana calon donatur tersebut. Untuk analisis harapan donatur, DPUDT memiliki tim silaturahmi kepada donatur-donatur potensial.

Untuk segmentasi, DPUDT segmentasi penghimpunannya berskala nasional. DPUDT untuk memhimpun dana dari luar negri memiliki direct advertising yang di tempatkan di negara-negara lain. Untuk membangun citra lembaga kepada muzaki, DPUDT membuat program ke dalam bentuk-bentuk pilar. Sehingga muzaki bisa menilai DPUDT dari pilar-pilar tersebut.

Program pendayagunaan yang dilakukan oleh DPUDT, yaitu: dakwah KU (baitul qur'an, mobil cinta masjidku, media dakwahku, dan majlis talim manajemen qolbu), Ikhtiar KU (misykat, usaha ternak mandiri, usaha tani mandiri), Beasiswa KU (beasiswa TK/Paudku, Sdku, SMPku, SMKku, SMAku, bea mahasiswaku, dan balai kratifku), Peduli KU (layanan peduli sosial, layanan peduli kemanusiaan, Ramadhan peduli negeri, qurban peduli negeri, dan peduli lingkunganku).

Metode promosi dan sosialisasi di DPUDT, yaitu dengan memasang iklan di televisi berskala nasional di bulan Ramadhan, dan televisi berskala lokal di bulan-bulan biasa. Menggunakan kedua metode promosi dan sosialisasi baik langsung maupun tidak langsung. Metode fundraising langsung adalah presentasi dan sosialisasi langsung ke muzaki potensial, mengadakan kajian-kajian rutin yang di isi oleh aa Gym (pimpinan pondok pesantren Darut tauhiid), dan bersilaturahmi ke rumah atau perusahaan yang dianggap donatur potensial. Metode fundraising tidak langsung adalah memasang iklan di televisi berskala nasional maupun lokal dan di radio.

Teknik layanan donasi yang dilakukan oleh DPUDT yaitu transfer lewat ATM, jemput zakat langsung ke muzaki, dan datang langsung ke counter-counter DPUDT yang sudah tersedia di wilayah yang ditentukan. Strategi pelayanan donatur yang dilakukan DPUDT adalah bersilaturahim ke donatur potensial setiap 1 bulan sekali, memberikan informasi seputar tentang zakat yang disalurkan, dan memberikan majalah DPUDT kepada donatur untuk mengetahui kegiatankegiatan DPUDT. 
Tabel 16. Strategi Penghimpunan Dana Zakat DPUDT

\begin{tabular}{lrll}
\hline Faktor & Penentu & & \\
Keberhasilan & & & \\
$\begin{array}{l}\text { Penghimpunan } \\
\text { Zakat }\end{array}$ & Dana & $\begin{array}{l}\text { Tingkat } \\
\text { Kepentingan }\end{array}$ & Kenyataan \\
\hline
\end{tabular}

1. Analisis Profil dan Harapan Donatur

4

2. Segmentasi, Positioning, dan Pencitraan

3. Program Pendayagunaan

4. Metode Promosi dan Sosialisasi

5. Teknik Layanan Transaksi Donasi

6. Strategi

Pelayanan Donatur 4

garis tingkat kepentingan adalah variabel analisis profil dan harapan donatur, karena DPUDT sendiri masih mengambil marketnya menengah ke bawah. Sehingga DPUDT dikenal hanya dikalangan menengah ke bawah. Bagi garis kenyataan yang paling rendah adalah di teknik layanan transaksi donasi, DPUDT dalam melakukan teknik layanan transaksi donasi masih jauh dengan lembagalembaga zakat di atas. DPUDT hanya bekerja sama dengan beberapa bank saja untuk melakukan transaksi melalui bank, sementara lembaga zakat lain hampir sudah bekerja sama dengan semua bank yang ada di Indonesia seperti Dompet Dhuafa yang hampir bekerja sama dengan semua bank.

\section{KESIMPULAN DAN IMPLIKASI}

Berikut ini merupakan grafik spyderweb yang didapatkan dari data pada tabel 16.

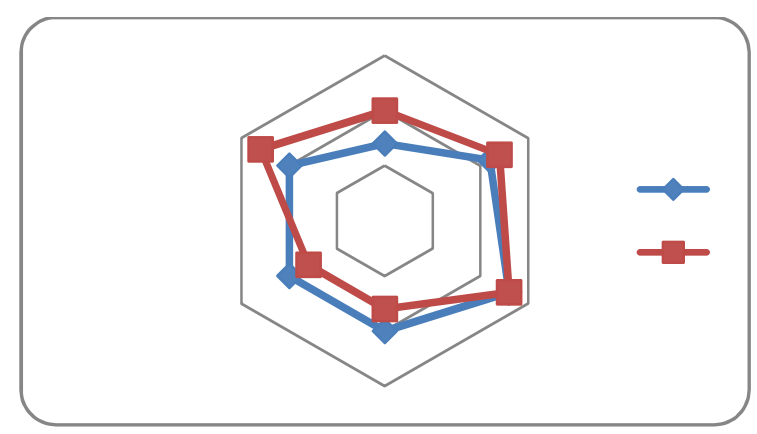

Gambar 6. Grafik Spyderweb DPUDT

Menurut DPUDT, tingkat kepentingan yang paling tinggi adalah di program pendayagunaan, bagi DPUDT programprogram pendayagunaan bisa juga dijadikan citra lembaga agar lebih membantu promosi kepada masyarakat. Kemudian Untuk garis kenyataan pada gambar 6. yang paling tinggi adalah strategi pelayanan donatur, menurut DPUDT pelayanan donatur itu penting agar muzaki bisa terus berdonasi ke lembaga zakat tersebut. Untuk nilai paling kecil pada

\section{Kesimpulan}

Berdasarkan penelitian yang telah dilakukan di lima lembaga pengelola zakat maka kesimpulan adalah sebagai berikut:

Strategi penghimpunan dana zakat yang dijalankan oleh lima lembaga pengelola zakat yang diteliti ternyata berbeda-beda, yaitu, BAZNAS Pusat dalam menjalankan strategi penghimpunan dana zakatnya melakukan proses-proses berikut, yaitu: sosialisasi langsung ke donatur individu maupun kelompok, membuat aplikasi muzaki conner, yaitu aplikasi untuk hp android dan iphone sehingga bisa memudahkan muzaki untuk membayarkan zakatnya secara langsung ke BAZNAS pusat tanpa mendatanginya jika ingin berdonasi zakat

Dompet Dhuafa dalam melakukan strategi penghimpunannya sudah sampai hingga skala internasional, karena sudah memiliki kantor cabang di berbagai negara seperti: Australia, Jepang, Korea, Amerika, 
dan Hongkong. Proses promosi dan sosialisasi yang dijalankan oleh Dompet Dhuafa menggunakan system ATL (above the line) dan BTL (below the line), serta direct compaign, yakni melaksanakan hubungan dan kerja sama dengan mal besar yang bersegmen B, A, A+. Tujuan kerja sama ini adalah untuk memberikan kemudahan kepada masyarakat muslim untuk melakukan pembayaran zakat dan donasi sekaligus memberikan pemahaman secara langsung kepada masyarakat segmen menengah ke atas.

PKPU dalam melaksanakan strategi penghimpunan dana zakat menggunakan program promosi marketing multi dimensi baik langsung maupun tidak langsung, media elektonik maupun cetak.

Strategi penghimpunan dana zakat di lembaga rumah zakat, yaitu: membuat iklan di media social dan pengiriman kabar kepada donatur. Untuk melakukan hubungan baik dengan pada donatur, rumah zakat memberikan layanan yang sesuai dengan kebutuhan para donatur, baik melalui media yang sudah dicantumkan oleh donatur itu sendiri seperti: WA, BB, dan yang lainnya.

DPUDT melakukan penghimpunan dana zakat berasal dari dalam dan luar negeri. Dari dalam negeri, strategi penghimpunan dana zakatnya dilakukan dengan cara membentuk tim silaturahmi kepada donatur potensial dan memasang iklan di radio darut tauhid. Sedangkan strategi penghimpunan dana zakat untuk luar negeri, yaitu: DPUDT memiliki orangorang yang dipilih dari darut tauhid untuk menghimpun dana zakat dari WNA dan WNI yang ada di luar negeri, atau sering disebut juga dengan direct advertising.

Setelah melihat data dan proses startegi penghimpunam dana zakat yang telah dilakukan oleh lima lembaga pengelola zakat, maka LPZ yang paling optimal melakukan strategi penghimpunan dana zakat adalah Dompet Dhuafa. Dari tahun ke tahun, Dompet Dhuafa menghimpun dana selalu meningkat tinggi dan relevan mengikuti kebutuhan masyarakat, sehingga Dompet Dhuafa dinyatakan sebagai lembaga yang paling optimal dalam penghimpunan dana zakat.

\section{DAFTAR PUSTAKA}

Sudewo,Ari. 2004. Manajemen Zakat. Jakarta. Institut Manajemen Zakat.

Ali, Mohammad Daud. 1988. Sistem Ekonomi Islam Zakat dan Wakaf Jakarta. Universitas Indonesia (UIPress).

Schiffman, Leon. Dan Kanuk, Leslie Lazar. 2008. Perilaku Konsumen. Indonesia. PT. Macanan Jaya Cemerlang.

Hafiduddin, Didin. Dan Juwaeni, Ahmad. 2006. Membangun Peradaban Zakat. Jakarta. Institut Manajemen Zakat.

Sabiq, Sayyid. 1978. Fiqh Sunnah. Bandung. PT. Alma'arif

A Muchaddam Fahham,"Paradigma Baru Pengelolaan Zakat di Indonesia", dalam Jurnal Kesejahteraan Sosial, Vol.III, No. 19/I/P3DI/Oktober/2011.

Mahmudi. 2009. Penguatan Tata Kelola dan Reposisi Kelembagaan Organisasi Pengelola Zakat. Volume 4 Nomor 1:69-84.

Zakiya, Kuni. 2014. Analisis Strategi Penghimpunan Dana dalam Mencapai Target Penerimaan Zakat. Skripsi. Surabaya. UIN Sunan Ampel

Yani, Dwi. 2008. Strategi Penghimpunan Dana Zakat oleh BAZNAS. Tesis. Jakarta. UI.

\section{Sumber Internet:}

www.BAZNAS.org www.DompetDhuafa.org 
www.dpu-daaruttauhiid.org

www.rumahzakat.org

www.pkpu.org 